\title{
Phonological coding by the prelinguistically deaf
}

\author{
B. DODD and B. HERMELIN \\ MRC Developmental Psychology Unit, Drayton House, Gordon Street, London, WCI, England
}

\begin{abstract}
A series of experiments was carried out to determine the type of linguistic input used by profoundly prelinguistically deaf subjects who had acquired a phonological code which enabled them to match homophones and identify rhymes. The results indicated that the tasks were primarily done by using visual information from lipreading, and that the subjects did not rely greatly on similarities of written representation, lexical information, or motor feedback from the articulators to perform the phonological matching tasks.
\end{abstract}

Recent experiments have shown that the omissions and substitutions which the deaf and partially hearing produce in spontaneous speech are often consistent, and follow much the same pattern as that of young hearing children (Dodd, 1976; Oller \& Kelly, 1974; West \& Weber, 1973). Different hypotheses about the form of the speech code used by the deaf have been put forward. Erber (1971) found that the provision of acoustic cues helped the profoundly deaf only minimally, though for all groups which he tested, recognition of words improved with the detection of acoustic cues. However, lipreading was the main source of information for the profoundly deaf.

Conrad (1972) assumed that deaf subjects who do not use an articulatory code use a written one instead. In a memory task, his hearing subjects confused words which sounded similar, whereas the deaf confused those words which looked similar in writing. Thus, he concluded that the deaf used a visualalphabetic memory code for words. A more recent experiment by Bellugi, Klima, and Sipple (1975) analyzed the confusion errors made by deaf children in relation to confusability of signs in the American Sign Language. They report that those signs which were similar in form were the ones which were confused. Another possible source of information might be derived from vibratory cues from hearing aids.

While it is reasonable to assume that all these sources of information will be used by deaf children, it seems nevertheless necessary to investigate their relative importance for the development of an articulatory code in the absence of hearing. The question is, therefore, which form of linguistic input, other than audition, is most readily mapped onto a phonological system? One indication that the profoundly deaf can make use of phonological information came from an experiment by Hermelin and O'Connor (1973), which was designed to test any tendency of deaf subjects to name pictures shown to them. In this study, the ability of the deaf to memorize paired associates of pictures whose names rhymed (e.g., chair-bear) and pairs of pictures randomly associated (e.g., girl-bus) was compared. Each subject was tested on both sets of pictures, i.e., those depicting words which rhymed and those which showed pictures whose names did not rhyme. The order in which these were presented was alternated between subjects. The children were instructed to remember which two pictures belonged together, and were allowed enough time to look through the series of 20 paired pictures. Following this, 10 pictures, 1 from each pair, were re-presented, and the subjects were given the remaining 10 picture cards and asked to place each under the one it went with before. Profoundly deaf children did significantly better when pairing pictures whose names rhymed than when pairing those whose names did not rhyme. The rhyming pictures could be matched simply by realizing that the rhyming of the name was the relevant feature, whereas the random pairs had to be remembered by rote memory. Therefore, a better performance with the rhyming than with the nonrhyming pairs indicates an awareness of the relevant stimulus aspect.

As phonological information is usually assumed to be accessible through the auditory modality, the ability to recognize rhymes [i.e., words in which there is "consonance of the terminal sounds" (Shorter Oxford English Dictionary (SOED), p. 1733)] would seem to be dependent on the matching of the acoustic form of words. If this were so, it would seem unlikely that profoundly deaf children should be able to extract "rhyme" as being salient. Waldren, Prosek, and Worthington (1975) found that hearing-impaired subjects were able to use lip-read information to enhance consonant recognition. However, the question remains whether the ability of the deaf to lip-read implies that they can use this information to generate a phonological code to identify written rhymes and homophones. Alternative codes which could be used might be based on similarities of 
written representation, kinaesthetic feedback from the vocal apparatus, or on information about rhyming on the basis of teaching and memory, i.e., a lexical store.

The aim of the four experiments presented in this paper was to test each of these possibilities to find which, if any, could account for the profoundly deaf's surprising phonological abilities.

\section{EXPERIMENT 1}

The aim of this experiment was to establish that deaf subjects extract the relevant feature "homophone" to perform a paired associate task. Homophones were defined as "words having the same sound but ... different symbols denoting the same group of sounds"' (SOED, p. 916).

\section{Method}

Subjects. Thirteen profoundly, prelinguistically deaf boys, with a mean age of 13 years 2 months (range 12 years 2 months to 14 years 0 months) acted as subjects. The boys were students at a secondary boarding school for the deaf, situated outside London. The same subjects were used for each of the four experiments.

Procedure. Written representations of 18 pairs of homophones, e.g., rain-reign, and 18 pairs of randomly associated words, e.g., than-train (for test word lists see Appendix 1) were used as stimuli. Each homophone word pair was matched with a randomly associated word pair for the same number of common letters in the same sequential positions in order to control for the similarities of spelling of the homophone pairs. For example, the homophone pair rain-reign has in common the first letter $r$, the third letter $i$, and the last letter $n$; their control randomly associated word pair than-train share in common an initial $t$, the third letter $a$, and the final letter $n$. The frequency of occurrence of homophone and randomly associated words was also matched according to Thorndyke and Lorge (1944).

Each subject was tested on both homophone and randomly associated word pairs, and the order in which these were presented was alternated between subjects. The subjects were shown a simultaneous display of the 18 pairs of written words (lowercase letters printed with black Letraset on white card) and instructed that they were to remember which two words belonged together. They were given time to read through the words, once, but were not allowed to verbalize the test words. The subjects were then presented with 18 words, 1 from each pair, given the other 18 words on flash cards, and asked to place each of the flash cards under the word it went with before. If subjects could reconstruct the homophone word pairs better than they could reconstruct the randomly associated word pairs, then they could not have been matching the homophone pairs according to similarities of spelling.

\section{Results}

The subjects made significantly fewer errors when reconstructing the homophone word pairs than they did when reconstructing randomly associated word pairs (Wilcoxon matched pairs signed-ranks test, $\mathrm{N}=12, \mathrm{~T}=5, \mathrm{p}<.005$ ). Out 234 trials, there were 71 errors on the homophone pairs $\bar{X}=5.5$, range $0-15)$, and on the randomly associated word pairs, there were 137 errors $(\bar{X}=10.7$, range 5-16).

The results show that subjects could extract the relevant feature of "homophone" and use it to reconstruct the homophone pairs. Since subjects made significantly more errors when reconstructing the randomly associated word pairs, they could not have been relying on similarities of spelling of the word pairs to do the task. Therefore, the first hypothesis, that the deaf can match homophones solely according to similarities of written representation must be rejected.

\section{EXPERIMENT 2}

The aim of this experiment was to determine whether the deaf subjects could be using a kinaesthetic memory of how the homophone pairs "felt" when they were articulated to do the matching task. If this was so, it would assume that the initial learning of the words would have been on the basis of having received reinforcement for producing a certain movement pattern of the articulators. If both words of a homophone pair were produced similarly consistently, then the recognition of phonic similarity could be based on a kinaesthetic-articulatory code.

\section{Procedure}

The same 13 subjects were asked to read aloud from a typed word list which consisted of the 36 homophone words arranged in random order. Their utterances were recorded on a Uher Royal stereophonic tape recorder. These utterances were transcribed by two independent judges. The judges were asked to decide whether or not both words in each of the 18 homophone pairs were pronounced by each subject the same or differently. That is, the subjects were not scored on how correctly they articulated the words but on their ability to produce both words of a homophone pair similarly. If the subjects could not articulate similarly those pairs of homophones that they could match in Experiment 1, then they must be using information other than kinaesthetic feedback from an articulation code to match homophones.

\section{Results}

Out of 234 examples of articulation of homophone pairs, the subjects articulated 133 pairs very differently, e.g., rain and reign were produced as [reIn] and [regan], sure and shore as [sa] and [ $\mathrm{Sa}$. Thus the subjects were able to pronounce less than half of the homophone pairs similarly. Moreover, the pairs which were pronounced similarly did not correspond necessarily to those which had been paired correctly in the written homophone matching task in Experiment 1.

It would therefore seem unlikely that subjects had been solely dependent upon information from kinaesthetical-articulatory feedback to match the homophone pairs presented in Experiment 1, and the second hypothesis can be rejected.

\section{EXPERIMENT 3}

This experiment was designed to test the ability of subjects to recognize rhyming nonsense syllables by lip-reading. 


\section{Procedure}

The stimuli were eight pairs of rhyming nonsense words and eight pairs of nonrhyming nonsense words (see Apppendix 2). The word pairs were presented in random order to the subjects, who were told: "I am going to say two nonsense words. If they don't rhyme, like dit and roop, say 'no.' If they do rhyme, like gat and lat, say 'yes." "If they asked, subjects were told that a nonsense word was not a real word, but a made up one. If subjects gave no response after the first presentation of a nonsense word pair, the experimenter presented it a second, and if necessary a third, time. Refusal to respond after the third presentation was counted as an error. Sometimes subjects spontaneously imitated the nonsense words as they were presented; this was not discouraged.

Two sets of data were gained from this experiment. First, a quantitative analysis was made of the number of rhyming and nonrhyming nonsense word pairs identified correctly. If the subjects could correctly identify pairs of nonsense words as either rhyming or not rhyming, it would indicate that they would be using phonological rather than remembered lexical information.

The second set of data was gained by relating the frequency of errors to the place of articulation of the final consonants of the word pairs. An experiment on the lip-reading abilities of normal subjects (Dodd, 1977) has shown that some sounds are easier to distinguish visually than others, and that sounds made at the same general place of articulation are easily confused.

It is then possible to predict that when subjects are dependent on visual information to identify a word pair as either rhyming or not rhyming, the frequency of occurrence of errors for any word pair will be related to the visual distinctiveness of the final consonants of that pair. Thus, for the rhyming pairs, fewest errors would be predicted where the final consonant was articulated at the front of the mouth (bilabials $/ \mathrm{p}, \mathrm{b}, \mathrm{m} /$ and labiodental $/ \mathrm{f} /$ ), and more errors would be expected when the final consonant was an alveolar $(/ \mathrm{l}, \mathrm{n}, \mathrm{st} /)$ or velar $(/ \mathrm{k} /)$. For the nonrhyming nonsense word pairs, fewest errors should occur where the two final consonants came from different places of articulation (e.g., bilabial $/ p /$ vs. velar $/ g /$, and most errors should occur where the two final consonants came from the same general place of articulation (i.e., three general places of articulation were used; front consonants $/ \mathrm{p}, \mathrm{b}, \mathrm{m}, \mathrm{f} /$, middle consonants $/ \mathrm{d}, \mathrm{n}, \mathrm{t}, \mathrm{l} /$, and back consonants $/ \mathrm{k}, \mathrm{g} /$ ).

Thus this experiment asked two questions. First, could profoundly prelinguistically deaf children identify pairs of nonsense words as either rhyming or not rhyming? As such nonsense words could not be items which were contained in a longterm memory store, the relevant phonological information could not have been stored lexically. Secondly, if rhyming nonsense words were recognized as such, was there any indication that this was done on the basis of a lip-reading code? If so, those words which were easy to lip-read should be identified better as rhyming than those which were difficult to lip-read.

\section{Results}

When subjects were asked to identify 16 pairs of nonsense words as either rhyming or nonrhyming, their mean correct score was 12.0 out of a possible 16 , range 7 to 16 , correct. When chance level is set at 8 correct out of 16 trials, then performance was significantly better than chance (unrelated $t=5.93$, $\mathrm{dfs}=24, \mathrm{p}<.001)$.

An error analysis, concerned with which of the rhyming word pairs were wrongly judged as not rhyming, revealed that fewest errors were made when the final consonant in pairs was either a bilabial $(/ \mathrm{p}, \mathrm{b}, \mathrm{m} /)$ or a labiodental $(/ \mathrm{f} /)$ sound (6 errors out of 52 trials, $11.5 \%$ error). Where the final consonant was an alveolar $(/ \mathrm{t}, \mathrm{d}, \mathrm{s}, 1, \mathrm{n} /)$ sound, there was a $53.9 \%$ error; and where the final consonant was a velar. $(/ \mathrm{k}, \mathrm{g} /)$, there was a $46.2 \%$ error. An analysis of which nonrhyming word pairs were most frequently wrongly perceived as rhyming revealed that fewest errors occurred when the two final nonrhyming consonants came from different places of articulation ( 8 errors out of 78 trials, $10.3 \%$ error). Where both final consonants of the nonrhyming pairs came from the same general places of articulation, there were 12 errors out of 26 trials, a $46.2 \%$ error.

The results thus show that, as the material in this experiment consisted of nonsense words and as the deaf subjects could identify rhyming pairs, they must have been able to do this on a nonlexical level, from a lip-read input. The finding that errors were most likely to occur when the final consonants were difficult to distinguish visually indicates that those homophone pairs in Experiment 1 which were difficult to distinguish visually should be more prone to error than those homophones that were easy to lipread. This hypothesis was tested in Experiment 4.

\section{EXPERIMENT 4}

The aim of this experiment was to see if subjects' ability to do the homophone matching task in Experiment 1 was related to the ease of lip-reading the homophones.

\section{Procedure}

The subjects had 18 written words, one from each of the homophone pairs, placed before them in random order. They were asked to point to the word said by the experimenter. That is, they had to lip-read the word and indicate its written representation. They were then asked to perform the same task on the other 18 words of each homophone pair. The order in which each set of 18 words were presented alternated between subjects. If the subjects did not respond to the first presentation of a word, the same word was presented a second and, if necessary, a third time. Failures to respond after the third presentation were counted as errors, as were incorrect identifications.

For the purpose of analysis of the errors made, the 18 homophone word pairs were divided into the 9 pairs easiest to lipread, and the 9 pairs hardest to lip-read according to the following criteria [derived from research on lip-reading abilities of hearing children, Dodd (1977)]. (1) If there was only one consonant in a word (which was neither a bilabial nor a labiodental), that word pair was classed as hard to lip-read. This lead to the following word pairs being classed as hard to lip-read; air/heir, eight/ate, weigh/way, nor/gnaw, key/quay, sure/shore. (2) If the initial consonant of a word was a velar or a palatal sound, and the final consonant was a palato alveolar, then that word was classed as difficult to lip-read, and so use/yews, court/caught, and suede/swayed were also classed as difficult to lip-read.

The remaining 9 pairs were classed as easy to lip-read (i.e., census/senses, world/whirled, time/thyme, curb/kerb, file/phial, bier/buyer, rain/reign, write/right, paw/pour).

An analysis of lip-reading errors was then carried out to see if, in fact, the two groups of homophone word pairs led to significantly different levels of errors. 


\section{Results}

A Wilcoxon test revealed that significantly fewer lip-reading errors were made on those words predicted to be easy to lip-read than on those words predicted to be hard to lip-read $(\mathrm{N}=13, \mathrm{~T}=0$, $\mathrm{p}<.005$; mean error for easy pairs, 2.4 ; mean error for hard pairs, 4.9).

An analysis was then carried out to find out if subjects had made significantly more errors in Experiment 1 when matching homophone pairs which were difficult to lip-read than when matching those homophone pairs which were easy to lip-read. A Wilcoxon test was carried out on the raw error scores for the homophone matching task in Experiment 1, and it revealed that significantly more homophone matching errors were made on words hard to lip-read than on words easy to lip-read $(N=9, T=4, p<.025$; mean error for easy pairs, 2.3 ; mean error for hard pairs, 3.2). Note that when a Wilcoxon test was carried out on articulatory errors (Experiment 2) according to the two groups of homophones, it proved to be insignificant ( $\mathrm{N}=13, \mathrm{~T}=51$, n.s.).

The results indicate that the ability to do the homophone matching task in Experiment 1 is related to the ease with which the homophones could be lip-read. The hypothesis that the deaf gain phonological information primarily from how words look when they are said seems to be supported by these findings.

\section{DISCUSSION}

The results of the four experiments reported lead to the conclusion that the profoundly deaf subjects tested were primarily dependent on a visual input from lip-reading to gain phonological information which allowed them to match homophones and identify rhymes. This finding is in agreement with the results of a previous experiment (Dodd, 1976), which indicated that profoundly deaf subjects were using a visual input to map their phonological output.

The results seem less surprising if considered in the context of the role vision plays in the speech perception of normal hearing persons. Several experiments (Binnie, Montgomery, \& Jackson, 1974; Dodd, 1977; Sumby \& Pallock, 1954) have shown that the hearing can lip-read surprisingly well, and rely upon visual cues for information about front consonants $(/ p, b$, $\mathrm{m}, \mathrm{f}, \mathrm{v}, \theta /$ ) and place of articulation of consonants if the auditory channel is masked by quite low levels of noise. Since the hearing can use visual cues to complement hearing to perceive speech, it seems likely that the deaf can also gain phonological information by lip-reading.

While no evidence was obtained in the experiments reported here that the deaf could use information from similarities of written representation, lexical information, or motor feedback alone to match homophones, it is possible that information from these three sources may have provided additional cues. The subjects tested had had at least 7 years of "oralist" oriented education and their educational experience probably determined the way in which they did the tasks. Different educational experience might result in other channels being used to gain similar phonological capabilities.

The major implication of the findings is that the ability to store and use phonological information is not necessarily dependent upon the auditory modality. This may indicate that the way in which phonological information is stored is not modality specific. That is, no matter which modality of input is used to acquire phonological information, if it can be acquired it can be used to solve phonological tasks, such as the ability to recognize rhymes, homophones, and the mapping of phonological systems. Obviously, for normal hearing people, the visual channel is less efficient than the auditory channel in acquiring phonological information, but lack of an auditory input does not preclude such acquisition.

\section{APPENDIX 1}

Pairs of Words Used as Stimuli for Experiment 1

\begin{tabular}{llll}
\multicolumn{2}{c}{ Homophone Pairs } & \multicolumn{2}{c}{ Control Pairs } \\
air & heir & sew & flew \\
paw & pour & pie & pond \\
weigh & way & chain & cup \\
key & quay & cat & slot \\
ate & eight & aye & empty \\
caught & court & bright & built \\
shore & sure & chose & case \\
write & right & every & velar \\
rain & reign & than & train \\
swayed & suede & thirst & teats \\
gnaw & nor & blot & leg \\
bier & buyer & snare & sire \\
use & yews & key & lyre \\
file & phial & jets & pleat \\
curb & kerb & brow & stow \\
time & thyme & pine & phone \\
world & whirled & spins & shrinks \\
census & senses & wrings & drinks
\end{tabular}

\section{APPENDIX 2}

Pairs of Rhyming and Nonrhyming Nonsense Words

\begin{tabular}{llll}
\multicolumn{2}{c}{ Rhyming } & \multicolumn{2}{c}{ Pairs } \\
kwarn & sparn & vump & maf \\
mib & dib & gred & zam \\
yin & min & huk & spid \\
pembal & fembal & kend & pref \\
wek & lek & yemet & dumil \\
gaf & taf & nid & geb \\
vust & nust & blep & veg \\
hif & zif & kef & plaf
\end{tabular}




\section{REFERENCES}

Belluji, U., Klima, E. S., \& StPle, E. Remembering in signs. Cognition, 1975, 3, 93-125.

Binnie, C. A., Montgomery, A. A., \& Jackson, P. L. Auditory and visual contributions to the perception of consonants. Journal of Speech and Hearing Research, 1974, 17, 619-630.

ConRad, R. Short-term memory in the deaf: A test for speech coding. British Joumal of Psychology, 1972, 63, 173-180.

DoDD, B. The phonological systems of deaf children. Journal of Speech and Hearing Disorders, 1976, 41, 185-198.

Dodd, B. The role of vision in perception of speech. Perception, 1977 , in press.

ERBER, N. P. Auditory and audiovisual reception of words in low frequency noise by children with normal hearing and by children with impaired hearing. Journal of Speech and Hearing Research, $1971,14,496-511$.

HeRMELIN, B., \& O'Connor, N. Ordering in recognition memory after ambiguous initial or recognition displays. Canadian Journal of Psychology, 1973, 27, 191-199.
Oller, D. K., \& Kelly, C. A. Phonological substitution processes of a hard of hearing child. Journal of Speech and Hearing Disorders, 1974, 39, 65-74.

Sumby, W. H., \& Pallock, I. Visual contribution to speech intelligibility in noise. Joumal of the Acoustical Society of America, 1954, 26, 212-215.

ThorNDYKe, E. L., \& LORGE, I. The teacher's word book of 30,000 words. New York: Teachers College Press, Teachers College, Columbia University, 1944.

Waldren, B. E., Prosek, R. A., \& Worthington, D. W. Auditory and audiovisual feature transmission in hearing impaired adults. Joumal of Speech and Hearing Research, 1975, 18, 272-279.

WEST, J., \& WEBER, J. A phonological analysis of the spontaneous language of a 4 year old hard of hearing child. Journal of Speech and Hearing Disorders, 1973, 38, 25-35.

(Received for publication June 28, 1976; revision accepted January $18,1977$. ) 